TITLE:

\title{
Microcredit games with noisy signals: Contagion and free-riding
}

$\operatorname{AUTHOR}(S)$ :

Kono, Hisaki

\section{CITATION:}

Kono, Hisaki. Microcredit games with noisy signals: Contagion and freeriding. Journal of the Japanese and International Economies 2014, 33 : 96-113

\section{ISSUE DATE:}

2014-09

URL:

http://hdl.handle.net/2433/189387

\section{RIGHT:}

(c) 2014 Elsevier Inc.; This is not the published version. Please cite only the published version.; この論文は出版社版でありません。引用の際に は出版社版をご確認ご利用ください。 


\title{
Microcredit Games with Noisy Signals: Contagion and Free-Riding *
}

\author{
Hisaki Kono ${ }^{\dagger}$ \\ Kyoto University
}

December 4, 2013

\begin{abstract}
The advent of microcredit financing has remarkably improved access to credit for the poor in many developing countries. Although several microcredit programs have adopted the joint liability scheme, economic theory suggests that joint liability could increase strategic default through contagion and free-riding. This paper aims at studying the extent of free-riding and contagion in joint liability lending. By using data from experimental repayment games conducted in Vietnam, with noisy signals that resemble actual microcredit programs, we found that subjects were motivated to free-ride under the joint liability scheme. While most empirical research in this area has focused on the problem of contagion, our findings point to the significance of investigating free-riding behavior under joint liability schemes. Analyses reveal that the free-riding tendency may be led by the irresponsiveness of repayment and shouldering behavior to the partner's seemingly strategic default in the previous round.
\end{abstract}

Keywords: microcredit; joint liability; free riding; contagion.

JEL Classification: C93; D71; O16

${ }^{*}$ I am grateful to the editor of this journal and the anonymous referee for their valuable suggestions and comments. I thank seminar participants at the 2012 GRIPS/TWID Conference and the 2012 NBERTCER-CEPR Annual Trio Conference for their constructive comments and suggestions that greatly helped in shaping the paper. This research was supported by the Institute of Developing Economies (IDE-JETRO) and the Japan Society for the Promotion of Science (KAKENHI 20730198). I would like to thank our research assistants Nguyen Thi Huyen Tram, Tran Thi Song Phung, Dang Van Trinh, Pham Thi Tam, Nguyen Mau Trung, Chau Thi Tu, and Nguyen Van Ba for their outstanding fieldwork.

${ }^{\dagger}$ Graduate School of Economics, Kyoto University, Yoshida-honmachi, Sakyo-ku, Kyoto, 606-8501, Japan. Phone: +81 (75) 753-3459. E-mail: kono@econ.kyoto-u.ac.jp. 


\section{Introduction}

Microcredit financing, or unsecured small loans, have remarkably improved access to credit for the poor in developing countries since the last two decades. According to Microcredit Summit Campaign (2013), as of 2011, 3,703 microfinance institutions (MFIs) had succeeded in reaching out to 195 million clients, 124 million of whom were among the poorest category at the time of initial loan disbursement. Most MFIs sanction loans under the joint liability scheme, whereby group members are jointly liable for loan repayment. This scheme is believed to be an important factor for achieving high repayment rates. Economists have theoretically proved that joint liability can solve the asymmetric information problem in lending to the poor without collaterals. ${ }^{1}$

However, some MFIs departed from this widely used joint liability scheme over the last decade. Randomized experiment by Giné and Karlan (2011) supports this trend by detecting no difference in repayment rates between joint liability centers and individual liability centers. Through a framed field experiment conducted in Vietnam, Kono (2013) finds that joint liability does not reduce, and sometimes increases, strategic default and default rates. Recent papers have provided evidence for contagion under joint liability in Mexico (Allen, 2012), India (Breza, 2012), and Pakistan (Kurosaki and Khan, 2012). They have noted that a borrower tends to choose the option of defaulting when other members in the same group are likely to default. Joint liability requires other group members to shoulder for the defaulting borrowers, discouraging them from repaying their own loans. Free-riding is the other, littlestudied and less-documented, incentive problem under joint liability. Since joint liability makes it necessary for other members in the group to help defaulting members, a borrower has the incentive to strategically default, expecting other members to shoulder for him/her. The purpose of this paper is to analyze the extent of contagion and free-riding. To the best of our knowledge, this is the first study to investigate both the problems of free-riding and contagion associated with joint liability lending. ${ }^{2}$

To identify contagion and free-riding, we rely on predictions from the economic theory. Contagion predicts less strategic default in cases where group members have higher income as it lowers the chances of shouldering for partners. On the contrary, free-riding predicts more strategic default in cases where the partners have higher income since it generates the

\footnotetext{
${ }^{1}$ See (Ghatak, 1999) for adverse selection, (Stiglitz, 1990) for moral hazard, and (Besley and Coate, 1995) for strategic default.

${ }^{2}$ Giné and Karlan (2011) observed the combined effect of strategic default and moral hazard. In this paper, we solely focus on the incentive for strategic default.
} 
belief that the partners have sufficient money to shoulder for the defaulting borrower. We use original data from our experimental repayment games conducted in the villages of central Vietnam to examine repayment behavior in both cases. ${ }^{3}$ Without experimental games, it will be difficult to capture free-riding behavior, especially in cases where shouldering of debts occurs through informal transfers and precedes the repayment date. ${ }^{4}$

Villages in rural Vietnam are geographically small and characterized by strong closeknit communities. Moreover, since joint liability requires strong social relationship among group members, subjects collected from such villages would be an appropriate sample to examine the behavior of microcredit clients. The games were played across a two-month period in August-September 2008 in a non-anonymous manner to resemble real microcredit settings where the group members know each other, thus, allowing them to utilize social sanctions outside the games. To address ethical concerns that may arise from the experiments negatively influencing social relationships, we introduced noisy income signals so the subjects could not perfectly know each other's decisions. Although we believe that this incomplete information setting is an adequately realistic portrayal, it may also lead to free-riding under individual liability. To account for this, we analyze repayment decisions under both joint liability and individual liability, and investigate the extent of free-riding and strategic default in both cases.

To make individual liability comparable with joint liability in cases where borrowers share income shocks, we have adopted the repeated game framework where borrowers under individual liability could also share income shocks. Incentives for repayment were given by dynamic incentives, or contingent renewal, wherein access to further receipt of loans by a borrower or group was subject to repayment of the current loan. Dynamic incentives play a key role in maintaining high repayment rates in actual microcredit programs (AlexanderTedeschi, 2006; Giné, Goldberg, and Yang, 2012).

Our results were consistent with free-riding under joint liability with precise signals. Our findings reveal that imprecise partner signals do not affect repayment decision, implying that the signals were not precise enough to be relied upon. We do not detect free-riding under individual liability. Furthermore, under the precise signal treatment, subjects did not

\footnotetext{
${ }^{3}$ Kono (2013) also uses the same data to compare strategic default rates under various schemes but does not focus on identifying contagion and free-riding behavior separately.

${ }^{4}$ Oo and Toth (forthcoming) provide another excellent example of using experimental games for economic analysis. They manipulate the market condition in the games to investigate a social institution of punishment as the cause of stagnancy of microenterprises.
} 
respond to the seeming tendency of strategic default, which might qualify free-riding as a rational choice.

The rest of the paper is organized as follows. Section 2 presents a conceptual model describing the incentives for contagion and free-riding under joint liability. Section 3 describes our experimental design. Section 4 explains our empirical methodology and Section 5 reports the results. Section 6 concludes.

\section{$2 \quad$ Model}

This section describes the repeated repayment game model used to clarify incentive problems under joint liability and individual liability. To keep the argument simple, we assume perfect monitoring, wherein the borrowers can observe partner incomes. We consider a group consisting of two risk-neutral borrowers, each with a loan comprising repayment amount $B .^{5}$ Since our purpose is to present borrower incentives for free-riding and contagion under joint liability, we do not consider lender decisions. Generally, lenders impose different interest rates for individual and joint liability. However, focusing on this will complicate the experimental setting, without contributing much to the argument on free-riding and contagion under study. Hence, we chose to vary the lending liability scheme, holding everything else fixed.

The incentive for repayment is provided by contingent renewal: borrowers can access future loans subject to repayment of current loans. Under individual liability, borrower $i=1,2$ is eligible to receive further loans only if borrower $i$ repays amount $B$. Under joint liability, borrower $i$ can receive further loans only if the group repays amount $2 B$, irrespective of $i$ 's own repayment record. ${ }^{6}$ The discount factor is denoted by $\delta$. We normalize the utility of not receiving loans (and thus, no investment) to be zero. There are no strategic interactions

\footnotetext{
${ }^{5}$ In this paper, we briefly introduce the results; for complete characterization of the model, you may refer to Kono (2013), who compares the frequency of strategic default under various schemes using the same experimental data.

${ }^{6}$ We restrict our study to simple joint liability and ignore the possibility of designing optimal joint liability contracts. Recent studies show the possibility of improving joint liability contracts by introducing partial joint liability. See Bhole and Ogden (2010) and Allen (2012), which may explain why some microcredit programs do not impose strict joint liability. Generally, models allow future credit access to depend on the repayment amount, in which case partial repayment would be observed in the equilibrium. Our analysis restricts its attention to simple contract structure in which future credit access depends solely on repayment of the due amount by the borrower or group. It should be noted that our results might not be directly applicable to cases of flexible joint liability contracts.
} 
among the borrowers outside the repayment games. ${ }^{7}$ Additionally, we assume that the borrowers cannot save and hence, previous earnings cannot be used to repay the current loan.

The investment funded by the loan generates a stochastic income $g_{i} \in[0, \bar{g}]$, which is i.i.d. (independent and identically distributed) over the borrowers and periods. Borrower decisions do not affect the realization of $g_{i}$ to exclude the moral hazard in investment. Borrowers only decide whether and how much to repay, and whether and how much to contribute for helping their partners. ${ }^{8}$

The timing of the stage game is as follows. After observing $\left(g_{1}, g_{2}\right)$, the borrowers simultaneously decide their repayment amount $r_{i}, i=1,2$, which are observed by both players. If $r_{i}=r_{j}=B$, then the stage game is over and both borrowers receive another loan in the next period. If $r_{i}=B$ but $r_{j}<B, j \neq i$, then borrower $i$ is asked whether she is willing to shoulder the deficit of $j, B-r_{j}$. Under joint liability, borrower $i$ cannot receive any more loans unless she shoulders $j$ 's deficit. Under individual liability, borrower $i$ is eligible to receive the next loan, irrespective of whether she shoulders $j$ 's deficit or not. In such cases, borrower $j$ can receive further loans only if borrower $i$ shoulders the deficit. If $r_{i}, r_{j}<B$, both borrowers default and are ineligible for further loans. We assume that the borrowers cannot enter into binding contracts and hence, any arrangement among them should be selfsustained by repeated interactions. ${ }^{9}$ We also assume $\delta E(g)<2 B$ to exclude the case where a borrower always prefers repaying in spite of persistent defaults by her partner.

The assumption of perfect monitoring enables the borrowers to observe both $\left(g_{1}, g_{2}\right)$ and $\left(r_{1}, r_{2}\right)$, and detect strategic default by partners. In cases where borrowers can only observe the repayment decision, and not partner incomes, ascertaining whether a default is strategic or not is based on inferences.

\footnotetext{
${ }^{7}$ This is a simplified and unrealistic assumption because borrowers in microcredit programs often live in the same village or area. In the experiment, subjects made their decision to invest and repay face-to-face and hence, could resort to some social sanctions outside the repayment games.

${ }^{8}$ Though our experimental procedure only requires borrowers to choose whether or not to shoulder their partner's loans, for generalization, we describe a model in which borrowers choose the amount of shouldering.

${ }^{9}$ This self-sustained risk-sharing mechanism is more often observed in developing countries than developed countries where there is less dependence on informal risk-sharing mechanisms outside family networks (Townsend, 1994). Knowledge of partner incomes or its signal with high precision also makes risk-sharing more common in rural villages of developing countries.
} 


\section{$2.1 \quad$ Joint liability}

Under joint liability, the group can access future loans only if it repays $2 B$. Consider the following "no strategic default" action profile. When the group has sufficient income, that is, $g_{i}+g_{j} \geq 2 B$, it repays $2 B$ in any of the following ways: (a) if both borrowers have sufficient income, they repay $B$ each; (b) if one of them, say $j$, has insufficient income, then $j$ repays partly by contributing what she has, and $i$ shoulders for her by repaying the deficit. In other words, (a) if $g_{i}, g_{j} \geq B$, then $r_{i}=B$; (b) if $g_{j}<B<g_{i}$ and $g_{i}+g_{j} \geq 2 B$, then $r_{i}=B$, $r_{j}=g_{j}$, and $d_{i}=B-g_{j}$. When the group does not have sufficient income, $g_{i}+g_{j}<2 B$, then there are no prospects of repaying $2 B$ and hence, both $i$ and $j$ choose to default. Referring to this action as $C$, the action profile $(C, C)$ corresponds to the case of no strategic default with risk-sharing. ${ }^{10}$

This action profile involves consideration of the following four cases separately: (i) $g_{i}, g_{j} \geq$ $B$; (ii) $g_{j}<B<g_{i}$ and $g_{i}+g_{j} \geq 2 B$; (iii) $g_{i}<B<g_{j}$ and $g_{i}+g_{j} \geq 2 B$; and (iv) $g_{i}+g_{j}<2 B$. In case (i), $r_{i}=r_{j}=B$ while $d_{i}=d_{j}=0$. In case (ii), $r_{i}=B, r_{j}=g_{j}$, and $d_{i}=B-g_{j}$, resulting in $a_{i}=2 B-g_{j}$. Case (iii) is the other way around and $r_{i}=g_{i}$, leaving $i$ zero payoff. In these three cases, the borrowers are eligible to receive further loans. In case (iv), $r_{i}=r_{j}=0$, with no future loans. Let $p_{1}, p_{2}, p_{3}, p_{4}$ be the probabilities of cases (i) to (iv), respectively, where $p_{2}=p_{3}$.

The borrower's expected payoff from playing $(C, C)$ in every period under joint liability can be expressed as follows:

$$
E V^{J, C C}=\frac{1}{1-\delta\left(p_{1}+2 p_{2}\right)}\left[E(g)-\left(p_{1}+2 p_{2}\right) B\right]
$$

To derive the condition under which the action profile $(C, C)$ is supported in a subgame perfect equilibrium (SPE), we consider a trigger strategy profile $\sigma^{J}$ in which borrowers play $(C, C)$ as long as no deviation occurs, switching to $(D, D)$ for all periods after any deviation, where $D$ denotes the action of not repaying. We only need to examine the conditions for which $\sigma^{J}$ has no profitable one-shot deviation (Mailath and Samuelson, 2006).

To derive the conditions for no strategic default, we need to specify what would happen if the group defaults. Let the amount borrower $i$ shoulders for borrower $j$ be $d_{i}$. The total contribution of borrower $i$ then becomes $a_{i}=r_{i}+d_{i}$. If the group defaults, borrower $i$ will lose $\gamma a_{i}$ where $\gamma \in[0,1]$. In reality, once a borrower repays $a_{i}$ to a MFI, it does not return

\footnotetext{
${ }^{10}$ One can think of other "risk-sharing" strategies that make consumption levels of both borrowers equal whenever $g_{i}+g_{j} \geq 2 B$. But with risk neutrality, the payoff from this strategy is the same as payoff from the action profile $(C, C)$.
} 
the repaid amount $a_{i}$ in case the group defaults. This corresponds to $\gamma=1$. On the contrary, Besley and Coate (1995) assumes that $\gamma=0$. This is likely in cases where the borrowers interact beforehand to communicate their repayment decision and reach an agreement. Note that once borrower $i$ repays $B, \gamma B$ is sunk when she decides on shouldering for her partner.

Now we briefly state the incentive problems borrower $i$ faces. First, consider case (i), $g_{i}, g_{j} \geq B$. The payoff from playing $C$ is $g_{i}-B+\delta E V_{i}^{J, C C}$. Consider a one-shot deviation in which the borrower repays $\phi B, \phi \in[0,1)$. The most profitable one-shot deviation would be $\phi>0$, since paying $\phi B$ can induce the partner to shoulder for borrower $i$ by reducing the amount the partner needs to shoulder for receiving the next loan. Given $\gamma B$ is sunk when borrower $j$ decides on whether to shoulder or not, borrower $j$ 's incentive to shoulder is greater when $\gamma$ is large. Moreover, borrower $j$ will shoulder even if $\phi=0$, if $\gamma$ is sufficiently large. Expecting borrower $j$ to shoulder, borrower $i$ would choose to default if $g_{j}$ is sufficiently large. This is an example of repayment decisions based on free-riding incentives.

On the contrary, in case (ii), $g_{j}<B<g_{i}, g_{i}+g_{j} \geq 2 B$, borrower $i$ is required to shoulder borrower $j$ 's deficit, $B-g_{i}$. Hence, if she decides to repay $B$, then she finally needs to contribute $2 B-g_{j}$ for obtaining further loans. This will discourage borrower $i$ from repaying if the value of $g_{j}$ is small. This is an example of how a negative shock to a group member could induce the whole group to default, indicating a contagion problem.

The condition that the action profile $(\mathrm{C}, \mathrm{C})$ is sustained in a SPE in case (i) is as follows:

$$
\delta E(g) \geq B+\frac{1-\delta\left(p_{1}+2 p_{2}\right)}{2 \delta\left(p_{1}+2 p_{2}\right)-1} \gamma B
$$

if $(2-\gamma) B-\delta E(g) \geq 0$, and

$$
\delta E(g) \geq \frac{1}{\delta\left(p_{1}+2 p_{2}\right)} B
$$

otherwise. The analogous condition in case (ii) is as follows:

$$
\delta E[g] \geq B+\left[1-\delta\left(p_{1}+2 p_{2}\right)\right] B .
$$

While strictness of the conditions (4) and (2) depends on the value of $\gamma$, condition (4) is less strict than condition (3). Larger the value of $\gamma$, more likely it is for $(2-\gamma) B-\delta E(g)<0$. Furthermore, condition (4) becomes more strict than (2) if and only if $\gamma>1-\frac{2 \delta\left(p_{1}+2 p_{2}\right)-1}{1-\delta\left(p_{1}+2 p_{2}\right)}$. Hence, when the value of $\gamma$ is large, the binding incentive constraint is free-riding. If $\gamma$ is small, contagion is the binding incentive constraint. It should be noted that if social sanctions are available, these constraints become less strict, eliminating the concern for free-riding and contagion. 


\subsection{Individual Liability}

Under individual liability, borrower $i$ can access future loans only if she repays her own repayment amount $B$. However, there may still be an incentive to shoulder for the defaulting partner, enabling access to future loans for the partner, anticipating shouldering in return in the event of possible future investment failure.

First, we consider the repayment decision when there are no partners for sharing risk. If $p=\operatorname{Pr}(g \geq B)$, the borrower's expected payoff from no strategic default strategy can be expressed as follows:

$$
E V^{I}=\frac{1}{1-\delta p}[E(g)-p B]
$$

If a borrower with $g_{i} \geq B$ defaults strategically, then she will gain $g_{i}$ and receive zero payoff afterwards. Strategic default will not occur if and only if $g_{i}-B+E V^{I} \geq g_{i}$, or

$$
\delta E(g) \geq B
$$

This condition is less strict than those under joint liability, depicted in cases (2)-(4).

Next, we consider the repayment decision under individual liability with voluntary risk sharing. Consider the following "risk-sharing" action profile: (a) if both borrowers have sufficient income, each repays $B$; (b) if one of them, say $j$, has insufficient income, but the group as a whole has sufficient income, then $j$ partially contributes in repayment and $i$ shoulders $d_{i}=B-g_{j}$; and (c) if the group as a whole has insufficient income, the defaulting members will not be shouldered. In other words, (a) if $g_{i}, g_{j} \geq B$, then $r_{i}=B$; (b) if $g_{j}<B<g_{i}$ and $g_{i}+g_{j} \geq 2 B$, then $r_{i}=B, r_{j}=g_{j}$, and $d_{i}=B-g_{j}$; and (c) if $g_{i} \geq B$ but $g_{i}+g_{j}<2 B$, then $r_{i}=B, r_{j}=0$, and $d_{i}=0$. We denote this action as $C^{\prime}$.

This action profile requires consideration of the following five cases separately: (i)' $g_{i}, g_{j} \geq$ $B$; (ii)' $g_{j}<B \leq g_{i}, g_{i}+g_{j} \geq 2 B$; (iii)' $g_{i}<B<g_{j}, g_{i}+g_{j} \geq 2 B$;(iv)' $g_{i}+g_{j}<2 B, g_{i} \geq B$; and (v)' $g_{i}+g_{j}<2 B, g_{i}<B$. The cases (i)' to (iii)' are equivalent to cases (i) to (iii) under joint liability. Case (iv) of joint liability is divided into two subcases. Under joint liability, once $g_{i}+g_{j}<2 B$, the game is over. However, under individual liability, even if $g_{i}+g_{j}<2 B$, borrower $i$ can still continue the game if $g_{i} \geq B$, although her partner cannot. Let probability of cases (iv)' and (v)' be $p_{41}$ and $p_{42}$, respectively, where $p_{41}+p_{42}=p_{4}$. Additionally, note that $p \equiv \operatorname{Pr}(g \geq B)=p_{1}+p_{2}+p_{41}$.

The borrower's expected payoff from always playing $\left(C^{\prime}, C^{\prime}\right), E V^{I, C C}$, can be expressed as follows:

$$
E V^{I, C C}=\frac{1}{1-\delta\left(p_{1}+2 p_{2}\right)} \frac{1}{1-\delta p}\left\{\left[1-\delta\left(p_{1}+2 p_{2}\right)\right] E(g)-(1-\delta p)\left(p_{1}+2 p_{2}\right) B-p_{41} B\right\}
$$


In case of perfect monitoring, individual liability is free from the problems of free-riding and contagion. First, consider case (i)', $g_{i}, g_{j} \geq B$, and a one-shot deviation in which $i$ repays $\phi B, \phi<1$. Under individual liability, as long as she repays her own loan, $j$ can obtain future loans, even if $j$ does not shoulder for $i$. Hence, $j$ has no incentive to shoulder for the deviating partner. The condition for no profitable one-shot deviation turns out to be $\delta E(g) \geq B$.

Next, consider case (ii)', $g_{j}<B<g_{i}, g_{i}+g_{j} \geq 2 B$. In this case, borrower $i$ can access future loans even if she does not shoulder for $j$. The condition for repayment without shouldering for $j$ is again $\delta E(g) \geq B$. Hence, contagion will not occur.

Under joint liability, risk-sharing among borrowers is less likely than joint liability. The condition for the risk-sharing arrangement to be self-sustained is as follows:

$$
\delta E[g] \geq B+\frac{1-\delta p}{\delta p_{2}}\left[1-\delta\left(p_{1}+2 p_{2}\right)\right] B
$$

which is more strict than conditions (2)-(4) under joint liability.

\subsection{Imperfect Public Monitoring}

We do not provide a model for repayment decision under imperfect monitoring and just underline the following observations.

First, borrowers cannot distinguish between strategic default and non-strategic default perfectly only by observing partners' signal. Both under joint liability and individual liability, borrowers might choose to strategically default expecting their partners to consider the default as a consequence of insufficient income instead, especially when the signal indicates low-income status. Hence, introducing imperfect monitoring would increase the incentive for free-riding both under joint liability and individual liability.

We believe that imperfect information is common even in rural villages. Although group members are well informed about partner incomes, they may usually have some signals on their income, rather than perfect information. As already observed, this may lead to free-riding even under individual liability. 


\section{Experimental Design}

\subsection{Experimental Games}

To investigate repayment decision, we use data from framed field experiments ${ }^{11}$ conducted in four rural villages in the Quang Ngai Province, one of the poorest provinces in Vietnam, over a two-month period in August-September 2008.

Games conducted as part of the experiment were based on the repeated game structure. Random groups were formed consisting of two or six players each. In each round, the subjects received loans to earn stochastic incomes $g_{i}$, and decided whether to repay $B$ or not after observing own income and signal of partner incomes. If some members in the group did not repay their own loans, the other members were asked to shoulder for them. As the contingent renewal condition was operational, defaulting individuals (under individual liability) or groups (under joint liability) were not allowed to advance to further rounds in the game. Moreover, points earned in previous rounds could not be used to repay the current loan. To mimic the infinite horizon games with discount factor $\delta$, we introduced the random stopping rule, wherein irrespective of subject choice, the game would end with the probability of $1 / 6$, that is, $\delta=5 / 6 .{ }^{12}$ After one game finished, the groups were reshuffled for the next game.

The experiments were conducted by using cards. At the beginning of the round, each subject received an envelope with three cards, representing "income." A card was either for 10 points or 0 points, and the three cards combined to a total of two 10 points cards and one 0 points card (20 points in total), one 10 points card and two 0 points cards (10 points in total), or no 10 points card and three 0 points cards (0 points in total). Hence, income $g$ took three possible values: $g \in\{0,10,20\}$. For the distribution of $g_{i}$, we conducted three treatments by letting $\mathbf{q}=\left(q_{20}, q_{10}, q_{0}\right)$ where $q_{g}=\operatorname{Pr}\left(g_{i}=g\right), g=0,10,20$, (i) $\mathbf{q}=(30,65,5)$, (ii) $\mathbf{q}=(50,25,25)$, and (iii) $\mathbf{q}=(60,20,20)$. On applying these parameter values to our theoretical model assuming perfect monitoring, the model predicts no strategic default under individual liability and occurrence of strategic default, irrespective of the value of $\gamma$, under joint liability. We set $\gamma=1$ corresponding to the situation that a MFI would not return the amount (partially) repaid in case of default. Furthermore, communication

\footnotetext{
${ }^{11}$ This terminology was introduced by Harrison and List (2004).

${ }^{12}$ Abbink, Irlenbusch, and Renner (2006) conducted finite horizon games, in which case choosing strategic default is only the equilibrium. In each round, our research assistants rolled a die and if the die cast one, the game was terminated even if the players repaid their loans.
} 
between the group members was allowed in some games. Since we did not find any significant difference in subject decisions across the distribution and communication treatments, we pool observations across communication and distribution treatments in the following analysis.

After receiving the envelope, subjects simultaneously communicated their repayment decision by submitting a card face down. Submitting a 10 point card indicated repayment and submitting a 0 point card implied no repayment. Repayment decisions were made faceto-face to resemble actual microcredit programs where group members usually know each other and publicly repay at regular meetings. Members were then asked to shoulder for defaulting members by submitting a 10 point card on their behalf.

To avoid any negative influence that the experimental games may have on the social relationship among the subjects, we introduced noisy income signals to ensure the subjects do not have perfect information about other members' decisions. The signals were written on the envelope, and although members could not observe partner incomes, they could observe the signals on the envelope. Every time we distributed the envelope, we reminded the subjects that the numbers on the envelope are signals associated with the income contained in the envelopes, and stressed on the precision of the signal. This particular aspect of the experiment was guided by the belief that actual microcredit borrowers cannot have perfect information about incomes of their partners and hence, this setting may be considered a good simulation of actual microcredit financing.

The following analysis focuses on two dimensions of the treatments.

Individual Lending vs. Joint Liability In the individual lending treatment, a subject would continue playing only if he/she repays his/her own loan (and the die does not cast one). In the joint liability treatment, a subject would continue playing only if the group as a whole repaid the total group loan amount.

Precision of the Signal To evaluate the importance of signal precision, we conducted two signal precision treatments: $75 \%$ precision and 90\% precision. More precise signal will give more precise information about whether the default was strategic or not, which will in turn affect the strategic default decision making.

Our focus is on studying the impact of partner income signals on repayment decision under joint liability and individual liability. Contagion predicts that if the signal indicates high realized income for the partner, a borrower will choose not to default strategically since she need not shoulder for her partner. On the contrary, free-riding predicts that 
signals indicating high partner income will offer the borrower free-riding incentives. We will investigate the distinction in response to signals between joint liability and individual liability, and precise signal and less precise signal.

\subsection{Recruitment of the Subjects}

We set up our lab in the local community office and instructed the village officials to recruit subjects for our experiment from poor households who are likely to be the target of governmental loans. ${ }^{13}$ We collected 360 subjects through this process.

Twelve subjects joined per session. When the subjects came to our lab, we conducted a series of experimental games, followed by a questionnaire survey. ${ }^{14}$ All rules regarding the experimental games were explained by using large poster boards before each game started. ${ }^{15}$ Games to be played were randomly assigned. The survey and experiment took two and a half hours to complete, with an average payout of 100,000 VND (approximately 6.2 USD), which was much higher than the urban experiment as it covered the transportation costs involved in travelling from the villages to the lab. Every 10 points were converted to 1,000 VND. The payment was made at the end of the session.

After collecting the data, we found that some subjects did not satisfy the criteria of microcredit clients in that they were either too young or too old, or too educated. We excluded subjects aged less than 18 or more than 65 and subjects with tertiary level education. That left us with 347 valid subjects.

Table 1 summarizes the characteristics of subjects used in our analysis. The first column presents the average characteristics of all the subjects that participated in the rural experiment. Rest of the columns report the weighted average of the characteristics of subjects who played each treatment. Since a subject played multiple individual or joint liability games, the observations reported below exceed the total number of subjects. Subject characteristics

\footnotetext{
${ }^{13}$ Government of Vietnam provides loans to poor households through the Agribank and the Vietnam Bank as part of its social policies. Their clients are similar to those of typical microcredit programs with the exception that the Agribank mainly provides agricultural loans repayable on harvesting.

${ }^{14}$ Though there is a possibility that the game outcomes might affect the answers to the questionnaire, we chose this order so that we could calculate the reward for each subject during the questionnaire survey. Conducting experiments followed by questionnaire survey is a standard procedure followed in lab experiments because they address the possibility of some questions in the questionnaire survey being affected by decisions in the experimental game.

${ }^{15}$ Appendix Figure presents the contents of the poster boards used for explaining rules of the joint liability games and individual liability games.
} 
are well balanced across the treatments and we found no statistically significant differences in demographic variables across the treatments.

Table 1: Summary of subject statistics across treatments

\begin{tabular}{lccccc}
\hline \hline Rural experiment & Total & IL & JL & $75 \%$ signal & $90 \%$ signal \\
\hline Female & 0.40 & 0.42 & 0.42 & 0.41 & 0.43 \\
& $(0.49)$ & $(0.49)$ & $(0.49)$ & $(0.49)$ & $(0.49)$ \\
Age & 41.86 & 41.49 & 41.71 & 41.30 & 41.76 \\
& $(10.80)$ & $(10.75)$ & $(10.88)$ & $(10.69)$ & $(10.88)$ \\
Education & 7.50 & 7.60 & 7.44 & 7.52 & 7.52 \\
& $(3.07)$ & $(3.08)$ & $(3.04)$ & $(3.10)$ & $(3.04)$ \\
Married & 0.92 & 0.91 & 0.92 & 0.91 & 0.92 \\
& $(0.27)$ & $(0.28)$ & $(0.27)$ & $(0.29)$ & $(0.27)$ \\
Risky Choice & 2.68 & 2.68 & 2.66 & 2.69 & 2.66 \\
& $(1.42)$ & $(1.44)$ & $(1.39)$ & $(1.40)$ & $(1.42)$ \\
GSS & 0.40 & 0.40 & 0.40 & 0.40 & 0.40 \\
& $(0.34)$ & $(0.32)$ & $(0.33)$ & $(0.32)$ & $(0.33)$ \\
Cooperate & 1.80 & 1.80 & 1.80 & 1.81 & 1.80 \\
& $(0.33)$ & $(0.33)$ & $(0.33)$ & $(0.34)$ & $(0.33)$ \\
\hline \hline Observations & 347 & 766 & 734 & 560 & 994 \\
\hline \hline
\end{tabular}

Standard deviations are in parentheses.

\section{Empirical Strategy}

There is ample heterogeneity across individuals in terms of their propensity to strategically default. To control for individual heterogeneity, we estimate the fixed effect linear probability model specified as follows: ${ }^{16}$

$$
\operatorname{Pr}\left(y_{i k t}=1\right)=\mathcal{T}_{i k} \theta+\mathcal{S}_{i k t} \gamma+\mathcal{T}_{i k} \mathcal{S}_{i k t} \beta+c_{i}+\eta_{k}+\zeta_{t}+\epsilon_{i k t},
$$

\footnotetext{
${ }^{16}$ Although probit or logit models are popular binary choice models, fixed effect probit is inconsistent. Fixed effect logit can produce consistent estimates, but with many categorical variables, and the iteration often does not converge.
} 
where $c_{i}$ represents the time-invariant individual effects, which depict the psychological unwillingness against strategic default and risk attitude, $\eta_{k}$ is the session order effect, $\zeta_{t}$ is the round effect, and $\epsilon_{i k t}$ depicts the remaining unobserved factors. $\mathcal{T}_{i k}$ is an indicator for joint liability and $\mathcal{S}_{i k t}$ denotes the signal contents. We run this regression separately for observations from the $75 \%$ and $90 \%$ precision signal treatments. The standard errors are clustered by sessions to allow for correlation between subjects in the same session.

We distinguish free-riding from contagion based on the response to the signal contents, $\mathcal{S}_{i k t}$, especially signals indicating high partner incomes. Free-riding implies more strategic default and contagion implies less strategic default in response to signals indicating high partner incomes. In addition to signals indicating high incomes (good signals), we also include signals indicating low partner incomes (bad signals). In the two-member group treatment, we define a signal to be good (bad) if the signal value is 20 (0). In the six-member group treatment, we define a signal to be good (bad) if the average value of the signals is not less than 12 (not greater than 8). A signal average of 12 indicates that the group has sufficient total income to shoulder a defaulting member, if the signals are correct. A signal average of 8 indicates absence of any prospects for repaying the group loan, if the signals are correct. Similar results are observed on using different cutoff values. In Appendix Table 1, we report the results of partner signals by defining signals as good (bad) if the average signal is no less than 14 (no greater than 6) or 16 (no greater than 4) in the six-member group treatment. $\beta$ reflects the difference in responses to signal contents under joint liability and individual liability, and the linear combination of $\gamma$ and $\beta$ capture the response to signal contents under joint liability, which is of primary interest to us. Note that free-riding can occur under individual liability in case of imperfect monitoring. This is captured by $\gamma$.

Our experimental design with contingent renewal gives rise to the econometric problem of attrition. Since defaulted individuals or groups could not continue in the game, we only observe the selected samples and attempt to minimize the attrition problem by restricting our sample to observations of the first four rounds only. We find that the results are robust to the change in this restriction. ${ }^{17}$ Moreover, given the relatively low default rate in our games, it appears that the sample selection problem may not be too critical.

To confirm that the sample selection problem is not significant in our case, we also report the results using inverse probability weighting (IPW) (Robins, Rotnitzky, and Zhao, 1995; Wooldridge, 2010) and assess if they are similar. The IPW allows for any correlation between the variable predicting the sample selection, say $\mathbf{z}_{i k t}$, and the error term $\epsilon_{i k t}$, but requires

\footnotetext{
${ }^{17}$ The results are available upon request.
} 
the following conditions:

$$
\begin{aligned}
& \operatorname{Pr}\left(s_{i k t}=1 \mid \mathbf{z}_{i k 1}, \ldots, \mathbf{z}_{i k t}, \epsilon_{i k 1}, \ldots, \epsilon_{i k t}, s_{i, t-1}=1\right)=\operatorname{Pr}\left(s_{i k t}=1 \mid \mathbf{z}_{i k t}, s_{i, t-1}=1\right), \\
& \operatorname{Pr}\left(s_{i k t}=1 \mid \mathbf{z}_{i k t}, s_{i, t-1}=1\right)>0 \text { for every value of } \mathbf{z}_{i k t} .
\end{aligned}
$$

The IPW weights each observation by the inverse of $\operatorname{Pr}\left(s_{i k t}=1 \mid \mathbf{z}_{i k t}, s_{i, t-1}=1\right)$. However, since the individuals or groups who default cannot play the following rounds, $\operatorname{Pr}\left(s_{i k t}=\right.$ $\left.1 \mid \mathbf{z}_{i k t}, s_{i, t-1}=1\right)$ would be zero for certain values of $\left(y_{i k, t-1}, \mathbf{x}_{i k, t-1}\right)$, violating condition (10). To avoid $\operatorname{Pr}\left(s_{i k t}=1 \mid \mathbf{z}_{i k t}, s_{i, t-1}=1\right)$ being zero, we restrict $\mathbf{z}_{i k t}$ to own repayment decision, own income, and the sum of partner incomes. Excluding the partner's repayment decision will invalidate our assumption (9), but we expect that the IPW will correct for sample selection to some extent. ${ }^{18}$

\section{Results}

\subsection{Strategic Default}

Table 2 summarizes the number of sessions and observations across the treatments. In total, we have 130 sessions, out of which 64 are joint liability sessions and 83 sessions are conducted with $90 \%$ precision signal. Since we set the probability of playing games with $75 \%$ precision signal as half the probability of playing with $90 \%$ precision signal games, the $75 \%$ precision signal treatment has smaller number of observations.

Moreover, since we investigate responses to partner signals, we only use the observations in which the partners are also playing the game. This excludes observations in the individual

\footnotetext{
${ }^{18}$ There are at least two other econometric procedures to correct for sample selection: Heckman-type procedure and bound analysis. Heckman-type procedure exploits the excluded variables, which determine sample selection but do not have direct impact on $y$. However, since strategy is in general a function of past variables and actions in a repeated game, any variable affecting attrition (e.g., own and partner incomes) could directly affect strategic default decision. Furthermore, even if we are willing to assume that past incomes do not directly affect current $y$, that only captures the sources of attrition (b) in the text and the estimator will not correct for sample selection bias caused by (c). The bound analysis proposed by Lee (2009) employs the trimming procedure, which provides the upper and lower bound on average treatment effects and requires neither the exclusion restrictions nor the conditions required for the IPW. However, this procedure does require the monotonicity assumption: the treatment assignment can only affect sample selection in "one direction" for all individuals. In our setting, this would require joint liability, for instance, to affect sample selection in the same direction for all individuals. This condition does not allow some subjects under joint liability to be more likely to default due to strategic default, and others to be less likely because of risk-sharing within the group.
} 
liability game where the partners defaulted and did not proceed in the game. This restriction makes joint liability and individual liability comparable because the players could potentially share income risk with their partners in both these treatments. This restriction leaves us with 3,662 round-level observations.

Table 2: Type of games

\begin{tabular}{lccccc}
\hline \hline & sessions & observations & $\begin{array}{c}\text { observation } \\
\text { with } g \geq B\end{array}$ & default rate & $\begin{array}{c}\text { \% of strategic default } \\
\text { (standard deviation) }\end{array}$ \\
\hline Individual liability (IL) & 66 & 1871 & 1588 & 0.198 & $0.055(0.229)$ \\
Joint liability (JL) & 64 & 1791 & 1547 & 0.197 & $0.070(0.256)$ \\
\hline $75 \%$ signal precision & 47 & 1283 & 1060 & 0.217 & $0.052(0.224)$ \\
$90 \%$ signal precision & 83 & 2379 & 2075 & 0.187 & $0.068(0.252)$ \\
\hline Total & 130 & 3662 & 3135 & 0.198 & $0.063(0.243)$ \\
\hline \hline
\end{tabular}

We define strategic default as no repayment when the subject, in reality, has enough income to repay, that is, $g \geq B$. However, with zero or inadequate income, the subject has no choice but to default. Excluding these observations, we are left with 3,135 observations. The average ratio of strategic default is $6.3 \%$. Low frequency of strategic default results in low variations in $y_{i k t}$. Hence, estimations using some subsample will suffer from relatively large standard errors. The overall default rate is $19.8 \%$, which is rather high compared to most microcredit programs. This might be caused because in our experimental games, risksharing occurs among borrowers only within the group, whereas in reality people have much wider risk-sharing networks. ${ }^{19}$

Table 3 examines how repayment decisions differ across the treatments by regressing strategic default on joint liability (JL); $75 \%$ precision signal treatment ( $75 \%$ signal); and an indicator for income of 20 points, the maximum investment return. Individual fixed effects, round effects, and session order effects are all controlled. Column (1) shows no significant difference in repayment decisions across the treatments. However, the interaction of signal treatment variable with joint liability reveals that joint liability increases strategic default when the signal is noisy, as shown in Column (3). The linear combination suggests that joint liability increased strategic default by 8.3 percentage points in the noisy signal treatment $(p<0.01)$. High income (income of 20 points) is always significantly positive at

\footnotetext{
${ }^{19}$ Another possibility is that actual distribution of investment returns is safer than our experimental distribution. In the income distribution treatment of $\mathbf{q}=(30,65,5)$, the default rate was much lower at 0.13 .
} 
1 percent levels across these specifications and this effect is somewhat stronger under joint liability. Columns (2) and (4) report the results using IPW, showing little change in the coefficients. Hence, we need not worry about sample selection and hereafter, report results using the fixed effect linear probability model.

Table 3: Strategic default

\begin{tabular}{lcccc}
\hline \hline & $(1)$ & $(2)$ & $(3)$ & $(4)$ \\
& $\mathrm{FE}$ & $\mathrm{IPW}$ & $\mathrm{FE}$ & $\mathrm{IPW}$ \\
\hline $\mathrm{JL}$ & 0.012 & 0.019 & 0.009 & 0.019 \\
& $(0.014)$ & $(0.015)$ & $(0.020)$ & $(0.021)$ \\
$75 \%$ signal & 0.002 & 0.006 & $-0.041^{* *}$ & $-0.039^{*}$ \\
& $(0.013)$ & $(0.016)$ & $(0.017)$ & $(0.023)$ \\
income=20 & $-0.082^{* * *}$ & $-0.086^{* * *}$ & $-0.062^{* * *}$ & $-0.062^{* * *}$ \\
& $(0.014)$ & $(0.022)$ & $(0.015)$ & $(0.021)$ \\
JL $\times 75 \%$ signal & & & $0.074^{* * *}$ & $0.076^{* * *}$ \\
& & & $(0.022)$ & $(0.028)$ \\
JL $\times$ income=20 & & & $-0.039^{*}$ & -0.046 \\
& & & $(0.023)$ & $(0.030)$ \\
\hline Observations & 3135 & 2874 & 3135 & 2874 \\
\hline \hline
\end{tabular}

Standard errors in parentheses

${ }^{*} p<0.10,{ }^{* *} p<0.05,{ }^{* * *} p<0.01$

\subsection{Contagion vs. Free-Riding}

We now investigate our main research question: free-riding and contagion under joint liability. Contagion implies more strategic default when the signal indicates low partner income (bad signal), and strategic default when the signal indicates good partner income. ${ }^{20}$ On the contrary, free-riding predicts more strategic default when the partner's signal is good. Free-riding can also occur under individual liability in the case of imperfect monitoring.

\footnotetext{
${ }^{20}$ When we assume risk-neutral borrowers, own income will not affect the repayment decision given partner income is fixed. But if borrowers are risk-averse, higher own income will increase the incentive to repay, which is consistent with the significantly positive coefficient on high income in Table 3.
} 
Columns (1) and (2) in Table 4 report our baseline results for $75 \%$ and $90 \%$ precision signal treatment, respectively. Good signal of partner is denoted by $\mathrm{p}$ :signal good. Hereafter, usage of the prefix $\mathrm{p}$ : in the tables indicates the partner's variable. In $75 \%$ precision signal treatment, the partner's good signal did not affect the decision to strategically default. The coefficients are close to zero, and there is no difference between response to the partner's good signal under individual liability and joint liability. This is plausible because the signals were not precise enough for the subjects to rely on. Interestingly, the partner's bad signal reduced strategic default under individual liability by 3.6 percentage points, which is significant at 10 percent level. On the contrary, in $90 \%$ precision signal treatment, we find a significant difference in the response to the partner's good signal. Compared to individual liability, the subjects under joint liability were more likely to default strategically when the partner's signal was good. The linear combination of the partner's good signal and its interaction term with joint liability is positive, which is consistent with free-riding, although marginally insignificant $(p=0.106)$. The negative but insignificant coefficient of the partner's good signal indicates no free-riding behavior under individual liability. Observations reveal that the partner's bad signal does not influence repayment decision under joint liability and individual liability. The results provide weak evidence for free-riding and no supporting evidence for contagion.

One may be concerned that the positive coefficient of the partner's good signal captures risk-sharing arrangements among group members in cases where a member with higher income transfers certain amount to a partner with lower income. Given the borrowers can receive transfers only when they do not repay and the partner shoulders for them in our game, the only way to receive transfers is to strategically default. We control for the risk-sharing effects by including the partner's default in the last round, ${ }^{21}$ or the cumulative balance of the borrower, which is defined as the number of times of shouldering (providing transfers) subtracted by number of times of being helped (receiving transfers) up to that round. Their interaction terms with joint liability and an indicator for the partner's good signal are also included. Ligon, Thomas, and Worrall (2002) demonstrated that current transfers depend on the history of transfers and increase the scope for risk-sharing. We hope that inclusion of the past default or cumulative balance would control for the risk-sharing effect.

Note that including these variables forces us to use observations from round two onwards, resulting in samples different than those in Columns (1) and (2). Hence, we report the results

\footnotetext{
${ }^{21}$ In the six-member group treatment, this variable takes the value one if any partner does not repay in the last round.
} 
Table 4: Strategic default: contagion vs. free-riding

\begin{tabular}{lcccccccc}
\hline \hline & $(1)$ & $(2)$ & $(3)$ & $(4)$ & $(5)$ & $(6)$ & $(7)$ & $(8)$ \\
& $75 \% \mathrm{sig}$ & $90 \% \mathrm{sig}$ & $75 \% \mathrm{sig}$ & $90 \% \mathrm{sig}$ & $75 \% \mathrm{sig}$ & $90 \% \mathrm{sig}$ & $75 \% \mathrm{sig}$ & $90 \% \mathrm{sig}$ \\
\hline p: signal good & -0.004 & -0.028 & -0.008 & $-0.047^{* *}$ & -0.010 & $-0.050^{* *}$ & -0.008 & $-0.055^{* * *}$ \\
& $(0.017)$ & $(0.018)$ & $(0.039)$ & $(0.019)$ & $(0.038)$ & $(0.019)$ & $(0.036)$ & $(0.019)$ \\
JL× p: signal good & 0.001 & $0.057^{* *}$ & 0.017 & $0.107^{* * *}$ & 0.017 & $0.109^{* * *}$ & 0.036 & $0.098^{* * *}$ \\
& $(0.030)$ & $(0.025)$ & $(0.061)$ & $(0.031)$ & $(0.060)$ & $(0.031)$ & $(0.058)$ & $(0.030)$ \\
p: signal bad & $-0.036^{*}$ & -0.027 & -0.005 & -0.010 & -0.006 & -0.010 & 0.004 & 0.064 \\
& $(0.021)$ & $(0.031)$ & $(0.024)$ & $(0.040)$ & $(0.024)$ & $(0.039)$ & $(0.028)$ & $(0.051)$ \\
JL× p: signal bad & 0.035 & 0.026 & 0.052 & 0.080 & 0.083 & 0.072 & 0.100 & 0.031 \\
& $(0.053)$ & $(0.043)$ & $(0.067)$ & $(0.060)$ & $(0.069)$ & $(0.058)$ & $(0.077)$ & $(0.086)$ \\
p: default (t-1) & No & No & No & No & Yes & Yes & No & No \\
Cumulative balance & No & No & No & No & No & No & Yes & Yes \\
\hline Observations & 1060 & 2075 & 613 & 1223 & 613 & 1223 & 613 & 1223 \\
\hline \hline
\end{tabular}

Standard errors in parentheses

${ }^{*} p<0.10,{ }^{* *} p<0.05,{ }^{* * *} p<0.01$

of the regressions in Columns (3) and (4), using observations from round two onwards. The results are similar to those in Columns (1) and (2). In case of the $90 \%$ precision signal treatment, depicted in Column (4), the coefficients of the partner's good signal and its interaction term with joint ability are still significant, and their linear combination becomes significantly positive $(p=0.013)$. This change in the significance level might reflect that once they repaid the loans in the first round, the borrower's belief in the partner's propensity to repay would strengthen. Moreover, since a borrower can free-ride only when the partner repays the loan, this belief would make the borrower more responsive to the partner's good signal.

Columns (5) and (6) report the results on inclusion of an indicator for the partner's default in the last round and its interaction term with the partner's good signal. These variables also interact with joint liability. The results are quite similar with those in Columns (3) and (4), and all of these newly added interaction terms are insignificant. In Column (6), the linear combination of the partner's good signal and its interaction term with joint liability is 0.059 , with p-value of 0.014. In Columns (7) and (8), we include the cumulative balance of the borrower, and its interaction terms with the partner's good signal and joint liability. These 
interaction terms are insignificant, and the linear combination of the partner's good signal and its interaction term with joint liability is significant at 10 percent level $(p=0.067)$. The coefficients of the partner's bad signal and its interaction term with joint liability are not significant in any specification. Overall, the observed patterns are consistent with free-riding and there is little evidence supporting contagion.

In Appendix Table 2, we have added indicator variables for own signal contents. The reference category is the signal indicating 10 points. Adding these variables has little effect on the coefficients of the partner's signal contents, since own signal contents and the partner's signal contents are independent. ${ }^{22}$

\subsection{Response to Free-riding}

Now we examine how the subjects responded to partner defaults and the seemingly freeriding behavior. Note that in the case of contagion, the entire group would default and hence, at no stage shouldering decisions for other members need to be made and there are no future rounds. Since the subjects could only observe the signals and could not precisely know if the partners defaulted strategically or not, we investigate the effect of the partner's seemingly strategic defaulting tendency, that is, defaults in cases when the partner's signal indicates availability of sufficient income to repay.

First, we investigate the likelihood of other members choosing to shoulder for the seemingly strategically defaulting partners. Table 5 reports the estimation results after including indicator variables for seemingly strategic defaulting members, that is, default by partners in cases where the signal was no less than 10, p:sig $\geq 10 \&$ default. Since subjects with sufficient income (i.e., 20 points) faced the decision to shoulder when some other members defaulted, only these select observations are used for analysis in this case. However, as long as players defaulted strategically expecting their partners to shoulder for them, and on an

\footnotetext{
${ }^{22}$ In case of the $95 \%$ precision signal, own bad signal (the signal indicating own income is zero) results in more strategic default. This may be caused because one can disguise strategic default as non-strategic default with own bad signal. This implies free-riding. However, one may argue that this reflects contagion, as borrower $i$ 's bad signal would induce the partner to default for avoiding high repayment burden. Moreover, borrower $i$, expecting this possibility, could choose to default. Additionally, note that the incentive to freeride is highest with own bad signal and the partner's good signal, and that the incentive to collude is highest with own and partner's bad signals. Columns (3) and (4) report the regression results, including (i) own bad signal with partner's good signal, and (ii) own bad signal with partner's bad signal. These terms and their interaction terms with joint liability never become significant, probably due to the small sample size satisfying (i) or (ii).
} 
average, this expectation is correct, the estimated coefficients would underestimate the true effects and hence, provide lower bounds.

In Columns (1) and (2), we only include the treatment variables. Despite the fact that we set $\gamma=1$, joint liability reduces the likelihood of shouldering in the $75 \%$ precision signal treatment case, instead of increasing it. Although joint liability has positive effect in the $90 \%$ precision signal treatment case, its effect is not significant. With less precise signals, joint liability does not necessarily induce risk-sharing among group members.

Table 5: Response to partner's default: Shouldering for other members

\begin{tabular}{|c|c|c|c|c|c|c|}
\hline & (1) & $(2)$ & $(3)$ & $(4)$ & $(5)$ & $(6)$ \\
\hline & $75 \%$ sig & $90 \%$ sig & $75 \%$ sig & $90 \%$ sig & $75 \%$ sig & $90 \%$ sig \\
\hline \multirow[t]{2}{*}{ JL } & $-0.246^{*}$ & 0.157 & $-0.313^{* *}$ & 0.174 & $-0.322^{* *}$ & 0.162 \\
\hline & $(0.132)$ & $(0.122)$ & $(0.141)$ & $(0.155)$ & $(0.144)$ & $(0.157)$ \\
\hline \multirow[t]{2}{*}{$\mathrm{p}: \mathrm{sig} \geq 10 \&$ default } & & & -0.010 & 0.065 & -0.087 & 0.051 \\
\hline & & & $(0.100)$ & $(0.083)$ & $(0.129)$ & $(0.111)$ \\
\hline \multirow[t]{2}{*}{$\mathrm{JL} \times(\mathrm{p}: \operatorname{sig} \geq 10 \&$ default $)$} & & & 0.154 & 0.001 & 0.296 & 0.060 \\
\hline & & & $(0.187)$ & $(0.147)$ & $(0.200)$ & $(0.172)$ \\
\hline \multirow[t]{2}{*}{$\mathrm{p}: \mathrm{sig}=20 \&$ default } & & & & & 0.108 & 0.037 \\
\hline & & & & & $(0.163)$ & $(0.142)$ \\
\hline \multirow[t]{2}{*}{$\mathrm{JL} \times(\mathrm{p}: \mathrm{sig}=20 \&$ default $)$} & & & & & -0.238 & -0.103 \\
\hline & & & & & $(0.237)$ & $(0.187)$ \\
\hline Observations & 245 & 378 & 245 & 378 & 245 & 378 \\
\hline
\end{tabular}

Standard errors in parentheses

${ }^{*} p<0.10,{ }^{* *} p<0.05,{ }^{* * *} p<0.01$

Columns (3) and (4) report the coefficients of variables indicating the partner's seemingly strategic defaulting tendency and its interaction terms with joint liability. The coefficients of these variables turn out to be insignificant in both $75 \%$ and $90 \%$ precision signal treatment cases. In this specification, the coefficient of joint liability captures the effect of default when the partner's signal is bad. The point estimate implies that when the partners defaulted with bad signals in case of the $75 \%$ precision signal treatment, the subjects were less likely to shoulder for them. Hence, we again observe that joint liability does not necessarily 
induce risk-sharing among group members if the signals are not so precise. ${ }^{23}$ In Columns (5) and (6), we add another indicator variable for the partner's default when the partner's signal indicated 20 point income, p:sig $=20 \&$ default. However, neither this term nor its interaction term with joint liability is significant and the results do not change.

Overall, the decision regarding whether to shoulder or not does not depend on whether partners defaulted strategically or not. This is still consistent with the trigger strategy where the punishment occurs in the next round since it would be optimal for the remaining borrowers to shoulder in order to obtain further loans given the sunk cost. ${ }^{24}$

Next, we examine how the seemingly strategic defaulting tendency affects future repayment decisions. In Columns (1) to (2) in Table 6, we include the partner's default in the last round. The results indicate that the partner's default affected the future repayment decision under joint liability only in the $75 \%$ signal treatment case. On the contrary, in case of the 90\%-precision signal, partner's default in the previous round did not affect the repayment decision.

Columns (3) and (4) investigate whether the partner's seemingly strategic defaulting behavior affected the future repayment decision. The results show that dependence on past defaults in the $75 \%$ precision signal case observed in Column (1) is driven by the response to the seemingly strategic defaulting tendency. Under individual lending, the partner's seemingly strategic defaulting tendency in the last round did not affect the repayment decision. On the contrary, the seemingly strategic defaulting behavior did not significantly affect the partner's future repayment decision in the $90 \%$ precision signal treatment case. This might justify choosing free-riding under joint liability in case of the $90 \%$ precision signal treatment because choosing strategic default would not trigger the partner to strategically default in the future. In Columns (5) and (6), we add an indicator variable which takes the value one if the partner's signal was 20 but she defaulted in the last round. Response to the partner's seemingly strategic defaulting tendency is concentrated on the case where the partners defaulted despite the signal indicating 20 point income in the $75 \%$ precision signal treat-

\footnotetext{
${ }^{23}$ It is also possible that it reflects the fact that subjects who defaulted with bad signals under joint liability were different from those who defaulted with bad signals under individual liability. We do not elaborate on the sample selection problem in this paper, because as we stated in the empirical strategy section, there are no valid ways to correct for sample selection in our experiment. Moreover, the number of observations used for assessing shouldering behavior is quite small.

${ }^{24}$ On using the ratio of partners who defaulted strategically, we find that subjects tend to shoulder for their partners when more partners defaulted strategically under joint liability. This result is driven by the fact that more members are required to shoulder as more partners chose to default.
} 
ment case. We still do not find any response to the partner's seemingly strategic defaulting tendency in the $90 \%$ precision signal treatment case, perhaps because of the accuracy of monitoring technology, which enables a player to induce the other partner to choose to act in a more cooperative manner by using a milder punishment (Matsushima, Tanaka, and Toyama, 2013).

Table 6: Response to partner's default: Future repayment decision

\begin{tabular}{|c|c|c|c|c|c|c|}
\hline & (1) & $(2)$ & $(3)$ & $(4)$ & $(5)$ & (6) \\
\hline & $75 \%$ sig & $90 \%$ sig & $75 \%$ sig & $90 \%$ sig & $75 \%$ sig & $90 \%$ sig \\
\hline \multirow[t]{2}{*}{$\mathrm{JL}$} & 0.006 & -0.010 & 0.005 & -0.011 & 0.009 & -0.012 \\
\hline & $(0.054)$ & $(0.021)$ & $(0.054)$ & $(0.021)$ & $(0.053)$ & $(0.021)$ \\
\hline \multirow[t]{2}{*}{ p:default $(\mathrm{t}-1)$} & -0.027 & 0.018 & -0.024 & 0.011 & -0.024 & 0.010 \\
\hline & $(0.025)$ & $(0.027)$ & $(0.031)$ & $(0.035)$ & $(0.032)$ & $(0.035)$ \\
\hline \multirow[t]{2}{*}{$\mathrm{JL} \times(\mathrm{p}:$ default $(\mathrm{t}-1))$} & $0.131^{* *}$ & 0.006 & 0.020 & -0.032 & 0.016 & -0.033 \\
\hline & $(0.056)$ & $(0.043)$ & $(0.051)$ & $(0.046)$ & $(0.051)$ & $(0.046)$ \\
\hline \multirow[t]{2}{*}{$\mathrm{p}: \operatorname{sig} \geq 10 \&$ default $(\mathrm{t}-1)$} & & & -0.006 & 0.012 & 0.018 & 0.018 \\
\hline & & & $(0.029)$ & $(0.046)$ & $(0.055)$ & $(0.055)$ \\
\hline \multirow[t]{2}{*}{$\mathrm{JL} \times(\mathrm{p}: \operatorname{sig} \geq 10 \& \operatorname{default}(\mathrm{t}-1))$} & & & $0.174^{* * *}$ & 0.073 & 0.039 & 0.109 \\
\hline & & & $(0.066)$ & $(0.068)$ & $(0.085)$ & $(0.098)$ \\
\hline \multirow[t]{2}{*}{$\mathrm{p}: \mathrm{sig}=20 \&$ default $(\mathrm{t}-1)$} & & & & & -0.033 & -0.010 \\
\hline & & & & & $(0.046)$ & $(0.065)$ \\
\hline \multirow[t]{2}{*}{$\mathrm{JL} \times(\mathrm{p}: \mathrm{sig}=20 \&$ default $(\mathrm{t}-1))$} & & & & & $0.207^{*}$ & -0.058 \\
\hline & & & & & $(0.108)$ & $(0.109)$ \\
\hline Observations & 1060 & 2075 & 1060 & 2075 & 1060 & 2075 \\
\hline
\end{tabular}

Standard errors in parentheses

${ }^{*} p<0.10,{ }^{* *} p<0.05,{ }^{* * *} p<0.01$

\section{Concluding Remarks}

Although joint liability schemes are widely adopted by microcredit programs, economic theory suggests that joint liability could increase strategic default through contagion and freeriding. Individual liability could also give rise to the free-riding problem under imperfect monitoring, although it would be free from contagion. By using experimental repayment 
games with noisy signals, which mimic actual microcredit programs, we found that subjects indeed have the tendency to free-ride under joint liability. While most empirical research has focused on the problem of contagion under joint liability, our results suggest the importance of investigating the free-riding behavior. We did not find any evidence for free-riding under individual liability. In all such cases, the decision of shouldering for partners and repayment in future rounds did not respond to the partner's seemingly strategic defaulting tendency, especially in case of the precise signal treatment. This may explain why subjects chose the free-riding option.

It should be noted that the incentive for free-riding largely depends on the parameter $\gamma$, the sunk portion of the repayment, while making the shouldering decision. In the experiment, we set $\gamma=1$, although this might not reflect the actual situation in some settings. However, this indicates that free-riding can be prevented by carefully designing microcredit contracts. Encouraging communication before repayment could resolve the free-riding problem, although it could increase chances of contagion. This suggests the imperative of analyzing the free-riding and the contagion problems simultaneously, and not separately, in joint liability programs, since a policy aiming to reduce free-riding may increase contagion. Future research in this area may investigate the relative importance of these two problems in real settings. 


\section{References}

Abbink, Klaus, Bernd Irlenbusch, and Elke Renner. 2006. "Group Size and Social Ties in Microfinance Institutions." Economic Inquiry 44 (4):614-628.

Alexander-Tedeschi, Gwendolyn. 2006. "Here Today, Gone Tomorrow: Can Dynamic Incentives Make Microfinance More Flexible?" Journal of Development Economics 80 (1):84105.

Allen, Treb. 2012. "Optimal (Partial) Group Liability in Microfinance Lending." .

Besley, Timothy and Stephen Coate. 1995. "Group Lending, Repayment Incentives and Social Collateral." Journal of Development Economics 46 (1):1-18.

Bhole, Bharat and Sean Ogden. 2010. "Group lending and individual lending with strategic default." Journal of Development Economics 91 (2):348-363.

Breza, Emily. 2012. "Peer Effects and Loan Repayment: Evidence from the Krishna Default Crisis." .

Ghatak, Maitreesh. 1999. "Group Lending, Local Information, and Peer Selection." Journal of Development Economics 60 (1):27-50.

Giné, Xavier, Jessica Goldberg, and Dean Yang. 2012. "Credit Market Consequences of Improved Personal Identification: Field Experimental Evidence from Malawi." American Economic Review 102 (6):2923-54.

Giné, Xavier and Dean S Karlan. 2011. "Group versus Individual Liability: Short and Long Term Evidence from Philippine Microcredit Lending Groups ."

Harrison, Glenn W. and John A. List. 2004. "Field Experiments." Journal of Economic Literature 42 (4):1009-1055.

Kono, Hisaki. 2013. "Is Joint Liability A Good Enforcement Scheme for Achieving High Repayment Rates ? Evidence from A Framed Field Experiment in Vietnam.” .

Kurosaki, Takashi and Hidayat Ullah Khan. 2012. "Vulnerability of Microfinance to Strategic Default and Covariate Shocks: Evidence from Pakistan." Developing Economies 50 (2):81115 . 
Lee, David S. 2009. "Training, Wages, and Sample Selection: Estimating Sharp Bounds on Treatment Effects." Review of Economic Studies 76 (3):1071-1102.

Ligon, Ethan, Jonathan P Thomas, and Tim Worrall. 2002. "Informal Insurance Arrangements with Limited Commitment: Theory and Evidence from Village Economies." Review of Economic Studies 69 (1):209-44.

Mailath, George J. and Larry Samuelson. 2006. Repeated Games and Reputations: Long-Run Relationships. Oxford University Press.

Matsushima, Hitoshi, Tomomi Tanaka, and Tomohisa Toyama. 2013. "Behavioral Approach to Repeated Games with Private Monitoring." CIRJE F-Series CIRJE-F-879, CIRJE, Faculty of Economics, University of Tokyo.

Microcredit Summit Campaign. 2013. Vulnerability: The State of the Microcredit Summit Campaign Report, 2013.

Oo, Alex and Russell Toth. forthcoming. "Using Framed Field Experiments to Understand Market Behavior in Developing Countries: Do Community-Sanctioned Social Pressures Constrain Microenterprise Growth?" Journal of the Japanese and International Economies .

Robins, James M., Andrea Rotnitzky, and Lue Ping Zhao. 1995. "Analysis of semiparametric regression models for repeated outcomes in the presence of missing data." Journal of the American Statistical Association 90 (429):106-121.

Stiglitz, Joseph E. 1990. "Peer Monitoring and Credit Market." World Bank Economic Review 4 (3):351-366.

Townsend, Robert M. 1994. "Risk and Insurance in Village India." Econometrica 62 (3):539591.

Wooldridge, Jeffrey M. 2010. Econometric Analysis of Cross Section and Panel Data, vol. 1. The MIT Press. 


\section{A Experimental Game Design}

Appendix Figure: Poster board used for instructing subjects in the experimental games

Joint Liability Game:

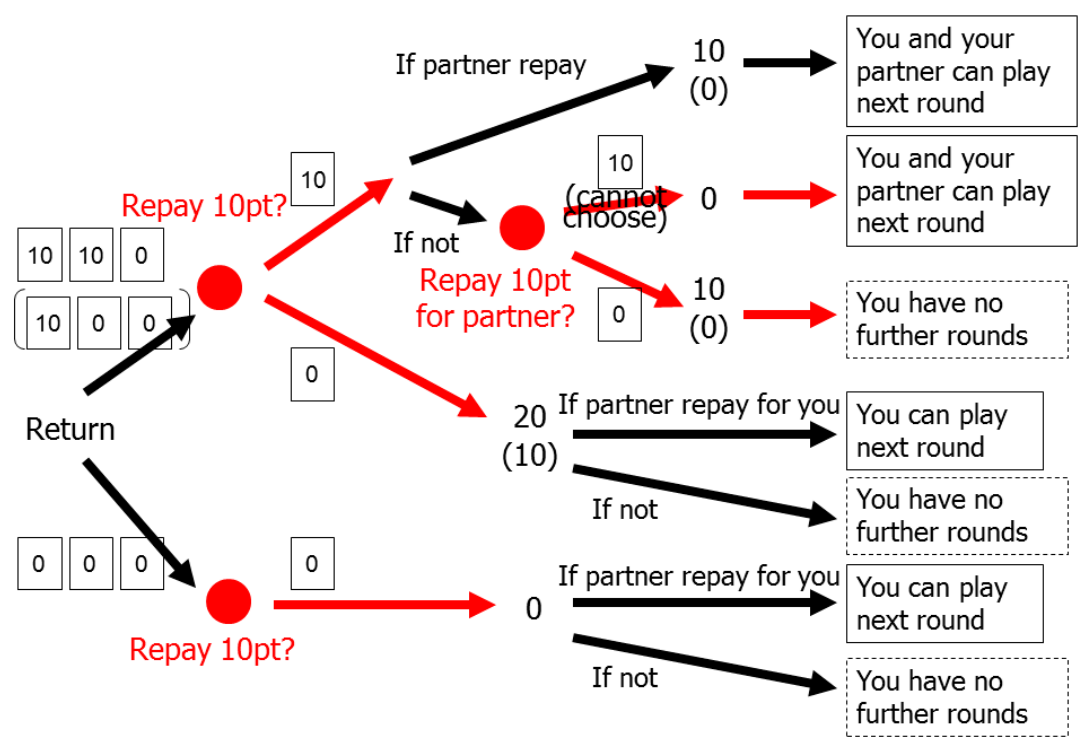

Individual Liability Game:

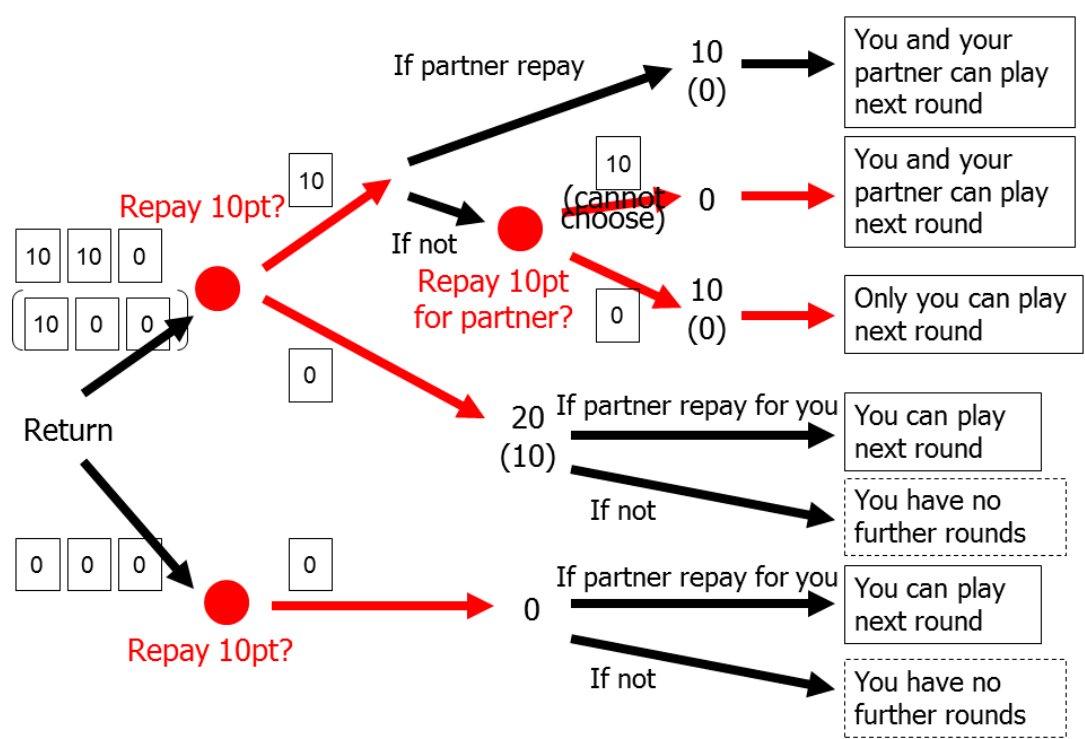


Table 1: Strategic default: using other threshold value for partner's good and bad signals

\begin{tabular}{lcccccccc}
\hline \hline & $(1)$ & $(2)$ & $(3)$ & $(4)$ & $(5)$ & $(6)$ & $(7)$ & $(8)$ \\
& $75 \%$ sig & $90 \%$ sig & $75 \%$ sig & $90 \%$ sig & $75 \%$ sig & $90 \%$ sig & $75 \%$ sig & $90 \%$ sig \\
\hline JL & 0.005 & -0.030 & -0.010 & -0.031 & -0.070 & -0.025 & -0.084 & -0.035 \\
& $(0.058)$ & $(0.026)$ & $(0.056)$ & $(0.025)$ & $(0.156)$ & $(0.031)$ & $(0.152)$ & $(0.029)$ \\
p: signal good & -0.003 & $-0.029^{*}$ & -0.016 & -0.022 & -0.022 & $-0.048^{* *}$ & -0.030 & $-0.051^{* * *}$ \\
& $(0.017)$ & $(0.017)$ & $(0.017)$ & $(0.016)$ & $(0.033)$ & $(0.019)$ & $(0.021)$ & $(0.018)$ \\
JL× p: signal good & 0.003 & $0.044^{*}$ & 0.023 & $0.043^{*}$ & 0.046 & $0.073^{* *}$ & 0.064 & $0.088^{* * *}$ \\
& $(0.025)$ & $(0.026)$ & $(0.025)$ & $(0.023)$ & $(0.048)$ & $(0.030)$ & $(0.049)$ & $(0.029)$ \\
p: signal bad & -0.025 & -0.019 & $-0.037^{*}$ & -0.029 & 0.016 & 0.067 & 0.005 & 0.040 \\
& $(0.021)$ & $(0.034)$ & $(0.022)$ & $(0.031)$ & $(0.039)$ & $(0.059)$ & $(0.040)$ & $(0.061)$ \\
JL× p: signal bad & 0.038 & 0.012 & 0.058 & 0.029 & 0.084 & 0.027 & 0.103 & 0.061 \\
& $(0.053)$ & $(0.046)$ & $(0.053)$ & $(0.044)$ & $(0.083)$ & $(0.096)$ & $(0.089)$ & $(0.103)$ \\
\hline Observations & 1060 & 2075 & 1060 & 2075 & 613 & 1223 & 613 & 1223 \\
\hline \hline
\end{tabular}

Standard errors in parentheses

${ }^{*} p<0.10,{ }^{* *} p<0.05,{ }^{* * *} p<0.01$ 
Table 2: Strategic default: contagion vs. free-riding

\begin{tabular}{|c|c|c|c|c|c|c|}
\hline & (1) & $(2)$ & $(3)$ & (4) & $(5)$ & (6) \\
\hline & $75 \%$ sig & $90 \%$ sig & $75 \%$ sig & $90 \%$ sig & $75 \%$ sig & $90 \%$ sig \\
\hline \multirow[t]{2}{*}{ p: signal good } & -0.005 & -0.027 & -0.008 & $-0.029^{*}$ & -0.009 & $-0.048^{* *}$ \\
\hline & $(0.017)$ & $(0.017)$ & $(0.019)$ & $(0.018)$ & $(0.038)$ & $(0.019)$ \\
\hline \multirow[t]{2}{*}{$\mathrm{JL} \times \mathrm{p}:$ signal good } & -0.000 & $0.057^{* *}$ & 0.002 & $0.060^{* *}$ & -0.004 & $0.108^{* * *}$ \\
\hline & $(0.029)$ & $(0.025)$ & $(0.028)$ & $(0.027)$ & $(0.057)$ & $(0.030)$ \\
\hline \multirow[t]{2}{*}{ p: signal bad } & $-0.037^{*}$ & -0.028 & -0.032 & -0.021 & -0.002 & -0.013 \\
\hline & $(0.021)$ & $(0.031)$ & $(0.020)$ & $(0.032)$ & $(0.027)$ & $(0.039)$ \\
\hline \multirow[t]{2}{*}{$\mathrm{JL} \times \mathrm{p}$ : signal bad } & 0.023 & 0.027 & -0.003 & 0.027 & 0.049 & 0.077 \\
\hline & $(0.050)$ & $(0.044)$ & $(0.046)$ & $(0.045)$ & $(0.064)$ & $(0.058)$ \\
\hline \multirow[t]{2}{*}{ own signal $=0$} & 0.014 & $-0.095^{* *}$ & -0.022 & $-0.138^{* *}$ & -0.018 & -0.043 \\
\hline & $(0.029)$ & $(0.043)$ & $(0.057)$ & $(0.067)$ & $(0.040)$ & $(0.049)$ \\
\hline \multirow[t]{2}{*}{$\mathrm{JL} \times$ own signal $=0$} & 0.052 & $0.181^{* *}$ & 0.059 & $0.231^{* *}$ & 0.099 & 0.100 \\
\hline & $(0.082)$ & $(0.076)$ & $(0.125)$ & $(0.117)$ & $(0.106)$ & $(0.105)$ \\
\hline \multirow[t]{2}{*}{ own signal $=20$} & 0.026 & 0.014 & 0.029 & 0.016 & -0.009 & -0.029 \\
\hline & $(0.027)$ & $(0.025)$ & $(0.027)$ & $(0.025)$ & $(0.037)$ & $(0.036)$ \\
\hline \multirow[t]{2}{*}{$\mathrm{JL} \times$ own signal $=20$} & $-0.101^{* *}$ & -0.018 & $-0.100^{* *}$ & -0.018 & $-0.105^{*}$ & -0.026 \\
\hline & $(0.045)$ & $(0.030)$ & $(0.045)$ & $(0.030)$ & $(0.063)$ & $(0.035)$ \\
\hline \multirow[t]{2}{*}{ own signal $=0 \& \mathrm{p}$ : signal good } & & & 0.063 & 0.104 & & \\
\hline & & & $(0.078)$ & $(0.072)$ & & \\
\hline \multirow[t]{2}{*}{$\mathrm{JL} \times($ own signal $=0 \& \mathrm{p}:$ signal good $)$} & & & -0.068 & -0.081 & & \\
\hline & & & $(0.157)$ & $(0.180)$ & & \\
\hline \multirow[t]{2}{*}{ own signal $=0 \& \mathrm{p}$ : signal bad } & & & 0.015 & -0.156 & & \\
\hline & & & $(0.076)$ & $(0.116)$ & & \\
\hline \multirow[t]{2}{*}{$\mathrm{JL} \times($ own signal $=0 \& \mathrm{p}:$ signal bad $)$} & & & 0.208 & 0.024 & & \\
\hline & & & $(0.230)$ & $(0.153)$ & & \\
\hline \multirow[t]{2}{*}{$\operatorname{partner}(\mathrm{P}) \operatorname{default}(\mathrm{t}-1)$} & & & & & 0.008 & 0.101 \\
\hline & & & & & $(0.041)$ & $(0.067)$ \\
\hline \multirow[t]{2}{*}{$\mathrm{JL} \times \mathrm{P}$ default $(\mathrm{t}-1)$} & & & & & $0.151^{* *}$ & -0.041 \\
\hline & & & & & $(0.069)$ & $(0.087)$ \\
\hline \multirow[t]{2}{*}{ p: signal good $\times$ default $(t-1)$} & & & & & -0.021 & -0.036 \\
\hline & & & & & $(0.056)$ & $(0.139)$ \\
\hline \multirow[t]{2}{*}{$\mathrm{JL} \times(\mathrm{p}:$ signal $\operatorname{good} \times \operatorname{default}(\mathrm{t}-1))$} & & & & & $-0.204^{* *}$ & 0.144 \\
\hline & & & & & $(0.090)$ & $(0.219)$ \\
\hline Observations & 1060 & 2075 & 1060 & 2075 & 613 & 1223 \\
\hline
\end{tabular}

Standard errors in parentheses

${ }^{*} p<0.10,{ }^{* *} p<0.05,{ }^{* * *} p<0.01$ 